SEXUAL HEALTH SERVICES

\title{
The 374 clinic: an outreach sexual health clinic for young men
}

\author{
D A Lewis, A McDonald, G Thompson, J S Bingham
}

See end of article for authors' affiliations

......................

Correspondence to: D A Lewis, Head of STI Reference Centre, National Institute of Communicable Diseases, Private Bag X4, Sandringham 2131

South Africa; david.lewis@ nhls.ac.za

Accepted for publication 17 July 2004
Sex Transm Infect 2004;80:480-483. doi: 10.1136/sti.2004.012138
Y oung men bear a disproportionate burden of acute sexually transmitted infections (STIs) in the United Kingdom. ${ }^{1}$ Published data in the United Kingdom show that the rates of acute STIs in young people are not equally distributed among ethnic groups in many inner city areas and are associated with material deprivation. ${ }^{2}$ The English national strategy for sexual health and HIV highlights the need to reduce inequalities in sexual health and specifically identified young men as a priority group for interventions and research. ${ }^{3}$ A number of current initiatives are under way, including enhanced sex and relationship education in schools, health promotion through the "sex lottery campaign," evaluation of different models of one stop shops, and development of young people's services across the country.

Young men are under-represented in attendances at genitourinary medicine (GUM) clinics. ${ }^{1}{ }^{3}$ Many young people choose not to attend such clinics when referred from community family planning services, even though they have been diagnosed with an STI. ${ }^{4}$ The aim of the 374 clinic service was to establish an outreach sexual health clinic targeted at young men under 25 years old which would offer both level two and three sexual health services, as in the national strategy for sexual health and HIV. ${ }^{3}$ This paper reports epidemiological and clinical data from the first 24 weeks of the service.

\section{METHODS}

\section{Establishment of the $\mathbf{3 7 4}$ clinic}

The 374 clinic, based at the London Brook premises at 374 Brixton Road in south London, opened in December 2003. The project involves collaborative partnership between staff of the GUM clinic at Guy's and St Thomas' Hospital NHS Trust and London Brook, a specialist non-statutory service providing contraception and sexual health screening to young people (mainly females). The clinic is staffed by male members of the GUM service: a consultant physician (DL/ JSB), an African-Caribbean liaison nurse specialist (AM), and receptionist (GT).

The 374 clinic operates on a Tuesday between 12-3 pm, on a day when the Brook clinic is closed to female clients, and offers sexual health screening to men under the age of 25 years on a walk-in basis. Posters and wallet sized cards were designed and printed to advertise the 374 service locally (fig 1). User views were not directly sought in the planning stages as the authors were aware of the findings of several focus groups, both published and unpublished, held with young men locally and nationally.

\section{STI tests, vaccinations, and treatments}

Contacts of chlamydia or gonorrhoea, as well as those patients with a urethral discharge or symptoms compatible with non-specific urethritis (NSU), had a urethral smear for Gram staining and a urethral culture for gonorrhoea performed. A first void urine sample was subsequently collected for chlamydia testing (ProbeTec ET Chlamydia trachomatis (CT), Beckton Dickinson). All other men were screened for chlamydial infection and gonorrhoea by urine based DNA amplification based tests performed at a private laboratory (Cobas Amplicor CT/NG test, Roche Diagnostics). Gram staining of urethral smears and microscopy were performed in a small laboratory area within the Brook clinic.

All young men were offered serological screening for syphilis and HIV infection. Herpes simplex culture and dark

Abbreviations: GUM, genitourinary medicine; NSU, non-specific urethritis; STI, sexually transmitted infections 


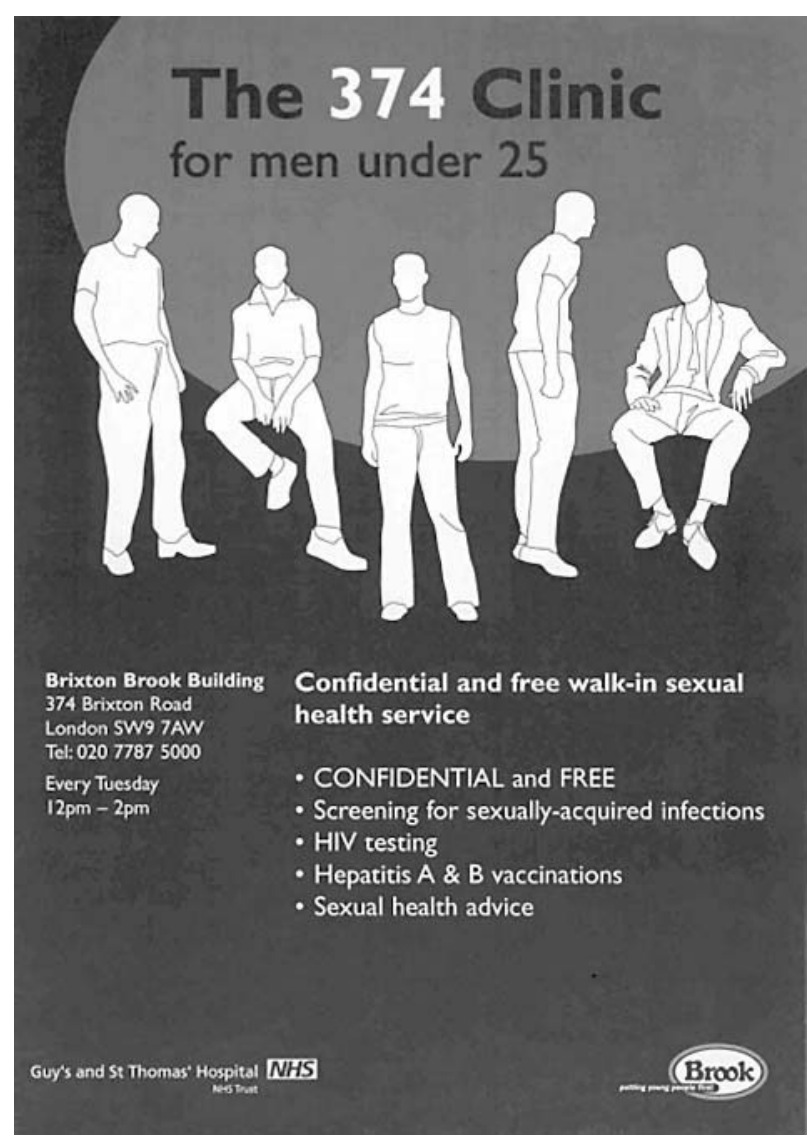

Figure 1 Poster for the 374 clinic.

ground microscopy facilities were available for those presenting with genital ulcers. Hepatitis A, B, and C antibody screening was undertaken for those at risk of these infections. Hepatitis A and B vaccinations were offered to men having sex with other men. Genital warts were treated with cryotherapy at the first visit; subsequent treatments were usually home based (podophyllotoxin $0.5 \% \mathrm{w} / \mathrm{v}$ ).

\section{Study design}

This study was retrospective and involved collection of demographic, clinical, and laboratory data for patients attending during the first 24 weeks of the service. All patients attending the clinic were included in the analysis. Data collected included the client's age, ethnic group, country of birth, first half of the postcode of residence, occupational status, contact details, permission to contact the client's general practitioner (GP), and the means by which the client had heard about the outreach service. Data were collected on STI and non-STI related diagnoses, treatments administered, laboratory tests performed, client preference for various methods of obtaining their results together with the relative success of each method, and referrals to other clinical services.

Ethics committee approval was not sought as the study was retrospective and used data from the clinical notes. The two tailed Fisher's exact test (with 95\% confidence intervals) was used to perform statistical analyses.

\section{RESULTS}

In the first 24 weeks, the total number of attendances at the clinic was 134, which included 94 new and 10 rebook patient visits. Most young men had heard about the clinic by "word

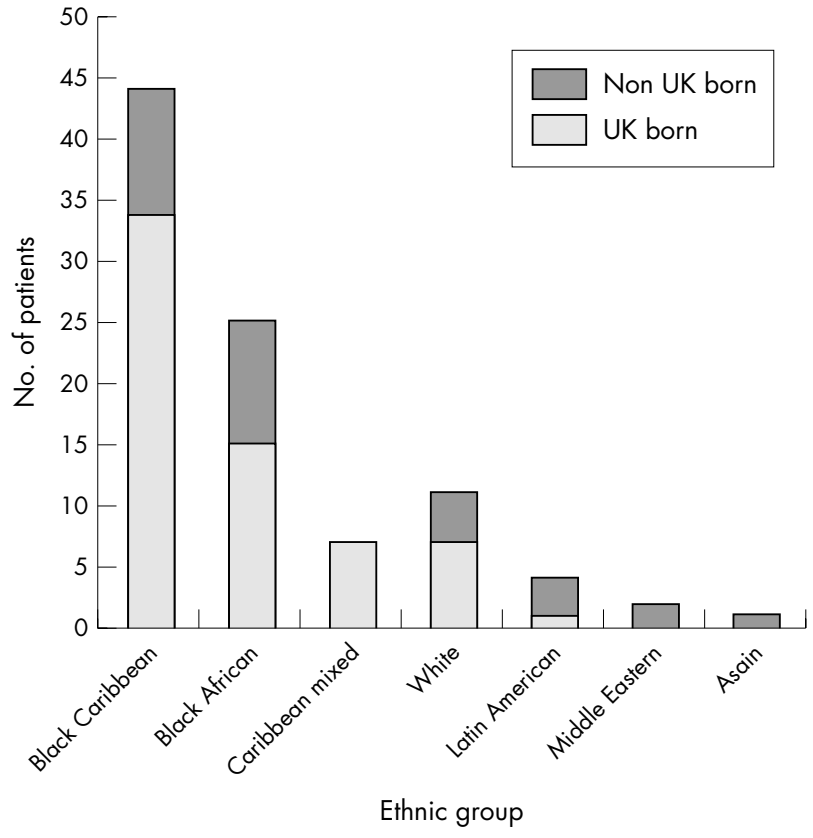

Figure 2 Ethnic groups of young men attending the 374 clinic, with relation to birth within or outside the United Kingdom.

of mouth" (42/92 clients, $46 \%)$, while others responded to either recommendation from local Brook services (18/92 clients, $20 \%$ ) or the 374 clinic promotional material (15/92 clients, 16\%).

The age range of young men attending was $12-27$ years (mean 18.2 years). Sixty three $(67 \%)$ of the young men were under 20 years old and $17(18 \%)$ were under 16 . With the exception of one bisexual male, all other young men had only experienced sexual intercourse with women (91) or had still to commence sexual activity (two). The data on patient ethnicity are shown in figure 2 . The majority of the patients lived in south London $(88,94 \%)$. Only $30(32 \%)$ were able or willing to provide details of their GP and 12 of these (40\%) specifically requested that their GP should not be contacted about their attendance. Most young men $(79,84 \%)$ had not previously been screened for STIs in either a GUM clinic or a primary care setting.

At first visit, 62/94 (66\%) young men reported that they had regular girlfriends, six of whom (10\%) were pregnant. Overall, $46(49 \%)$ patients had engaged in sexual intercourse with non-regular partners in the previous 3 months; $21 / 46$ $(46 \%)$ of these also had regular girlfriends. There was no statistically significant difference in "always using" versus "never using" condoms with either regular or non-regular girlfriends $(\mathrm{p}=0.21)$.

In respect of the 94 new patients, 44 (47\%) were symptomatic, 50 (53\%) were asymptomatic, 64 (68\%) requested a genital examination, and 92 (98\%) accepted screening for STIs; 73 (79\%) of these screens involved dual testing for both Chlamydia trachomatis and Neisseria gonorrhoeae using a first void urine specimen. Twenty one $(23 \%)$ patients had urethral microscopy performed; 19 of these ( $21 \%$ overall) had a urethral culture for gonorrhoea performed in addition to a screen for $C$ trachomatis using a first void urine specimen. Screening for syphilis was accepted by 62 (67\%) clients. HIV testing was requested by 55/76 (72\%) clients aged 16 and over compared to $5 / 16(31 \%)$ clients under 16 . One client, an exinjecting drug user, tested positive for hepatitis C IgG antibodies. 
Table 1 STIs and non-STI related conditions diagnosed at the 374 clinic

\begin{tabular}{|c|c|}
\hline Diagnoses & No of cases \\
\hline $\begin{array}{l}\text { STIs (in } 24 \text { patients) } \\
\text { Chlamydial infection* } \\
\text { Gonorrhoeat } \\
\text { Non-specific urethritis (NSU)† } \\
\text { Infectious syphilisł } \\
\text { HIV } \\
\text { Hepatitis C§ } \\
\text { Warts } \\
\text { Genital herpes } \\
\text { Pubic lice } \\
\text { Molluscum contagiosum } \\
\text { Other conditions (in } 6 \text { patients) } \\
\text { Psychosexual problems\$ } \\
\text { Balanitis } \\
\text { Fungal infections } \\
\text { Diabetic ketoacidosis }\end{array}$ & $\begin{array}{c}11(12 \%) \\
2(2 \%) \\
10(11 \%) \\
1(1 \%) \\
0(0 \%) \\
1(1 \%) \\
4(4 \%) \\
1(1 \%) \\
1(1 \%) \\
1(1 \%) \\
2(2 \%) \\
1(1 \%) \\
2(2 \%) \\
1(1 \%)\end{array}$ \\
\hline \multicolumn{2}{|c|}{$\begin{array}{l}\text { * } 7 / 11 \text { treated at the first visit as either NSU (5) or a known chlamydia } \\
\text { contact (3). } \\
\text { †All positive on microscopy. } \\
\text { fTreated at the GUM clinic (pretreatment RPR titre } 1 \text { in } 8 \text { ). } \\
\text { \$Referred elsewhere for specialist management. } \\
\text { - Referred to the GP. }\end{array}$} \\
\hline
\end{tabular}

Most young men (59 patients, $64 \%$ ) chose to receive their results by mobile telephone, others preferred to return to the clinic (30 patients, $33 \%$ ) or receive a postal letter in the event of any positive results (three patients, 3\%). Results were either given directly by telephone call or left as messages (with the patients' permission) on the first attempt in 52/59 $(88 \%)$ cases; a further five $(8 \%)$ cases were contacted successfully with a second call. Only 17/30 (57\%) of those young men who requested a results appointment returned to collect them.

A total of 27 diagnoses of STIs were made among 24 of the 92 new patients who underwent STI screening; no STIs were diagnosed in the 10 rebook patients (table 1). Chlamydial infection was significantly more prevalent in those men aged 20 years $(p=0.0039)$, although not significantly associated with patient ethnic group $(p=1.0)$. Five young men presented as chlamydial contacts; three subsequently had chlamydial infection confirmed. A hepatitis A and B vaccination programme was commenced for one bisexual client.

All patients with confirmed bacterial STIs, or contacts of such, were treated appropriately at the 374 clinic; the one client with presumed early latent syphilis was treated at the GUM clinic with intramuscular benzathine penicillin. Contact tracing was initiated in all cases of chlamydia, gonorrhoea, syphilis, and hepatitis C using contact slips. Contact tracing follow up for the 13 young men with confirmed bacterial STIs demonstrated that 12 (92\%) of them had informed their partners about their diagnoses and six $(46 \%)$ of them reported that their partners had been treated elsewhere.

\section{DISCUSSION}

The concept of GUM clinic staff working closely with the Brook organisation is not new ${ }^{5}$ although, to the authors' knowledge, the 374 clinic represents the first attempt, within the United Kingdom, to establish an outreach GUM clinic specifically for young men in collaboration with a community contraceptive and sexual health service. The Brook centre in Brixton was chosen for a number of reasons: it is situated within an area of Lambeth with high rates of gonorrhoea and chlamydia ${ }^{6}$; it possessed a laboratory space that was not in current use; many young women and an increasing number of young men feel comfortable accessing the Brixton Brook centre; a link with the Brook outreach team and other local Brook clinics offered the opportunity for referral of young men either directly or as male contacts of female Brook clients with diagnosed STIs.

Pearson conducted group discussions with young men and highlighted four key areas related to service image: client characteristics, service atmosphere, staff attitude, and confidentiality. ${ }^{7}$ The young men felt sexual health services were more orientated towards, and likely to be used by, women. They described family planning and GUM clinics as "clinical" and "unfriendly"; most thought young people's sexual health services were more "friendly." Those young men who had yet to visit services had stereotypical images of staff members as patronising and judgmental older women. They expressed a wish for staff to be young in outlook and to understand their lifestyles. Hancock reported that the young men in Derby wanted a safe, confidential, comfortable and male friendly environment. ${ }^{8}$ The Spaceman Project noted that "word of mouth" and outreach strategies were the main sources of young men finding out about it"; this has also been the experience of the 374 clinic.

Few young men currently access sexual health services and frequently do so to access free condoms or to deal with a crisis situation, such as gonococcal infection. ${ }^{79}$ It was encouraging to see that this was not so at the 374 clinic, where $53 \%$ of patients were asymptomatic at presentation. Well advertised condom provision for young people has been shown to be effective in encouraging male youths to access GUM services although many still remain reluctant to undergo screening for STIs. ${ }^{10}$ Based on this observation, the 374 clinic has a policy of only distributing condoms to those young men agreeing to see a health professional and provide a urine specimen for chlamydia and gonorrhoea screening. With this approach, all young men attending the clinic during the study period agreed to do this.

The national chlamydia screening pilot study suggests that $10-11 \%$ of women under 25 attending healthcare services may be infected with $C$ trachomatis ${ }^{11}$; equivalent community based prevalence data for chlamydial infection in men are lacking. A chlamydial infection rate of $6.8 \%$ was detected in a small of young men recruited at two further education colleges in Lambeth and Lewisham, ${ }^{12}$ almost half of the chlamydial infection rate ( $12 \%)$ seen in young men attending the 374 clinic.

There is no doubt that the use of non-invasive testing will improve the acceptability of screening for STIs to some young men. However, effective STI management of men with symptoms of dysuria and/or urethral discharge is greatly improved by access to on-site microscopy. This facility allows a same day diagnosis to be made for NSU, gonorrhoea, and primary syphilis. Positive microscopy findings enable same day treatment, appropriate health education, and early commencement of contact tracing. In this study, an STI was diagnosed and treated in 58\% of the Gram stained urethral smears examined.

Management of STIs in men within the community, rather than in GUM clinics, remains a challenge for several reasons, including the lack of on-site microscopy, lack of relevant staff experience, and the perception by many young men that community practices are not places where they would wish to discuss confidential sexual matters. A recent school questionnaire survey performed in central London reported that only $19 \%$ of teenagers said they would access sexual healthcare from their GP. ${ }^{13}$ Our own patients were reluctant to provide information about their GPs and, even when they did, $40 \%$ specifically requested the 374 clinic not to contact their GP.

This study demonstrates that, within the setting of a GUM outreach clinic, young men are happy to undergo both 
non-invasive STI screening and phlebotomy. Overall, $98 \%$ of clinic attendees accepted STI screening and $72 \%$ of those aged 16 and over also requested an HIV test, an uptake well above the $40 \%$ target set for the end of 2004 in the national strategy for sexual health and HIV. ${ }^{3}$ Based on feedback and reactions from the young men we have seen at the 374 clinic, as well as our colleagues at London Brook, we would support the concept of further GUM outreach clinics targeting young men in geographical areas with high STI rates.

\section{ACKNOWLEDGEMENTS}

The authors acknowledge the continued support and encouragement of the 374 clinic by Lynne Hurley and Denise Burrowes (London Brook), the Brook outreach team, and Simon James (Sexual Health Commissioner for Lambeth).

\section{CONTRIBUTORS}

DL wrote the manuscript, which was reviewed by JSB; all four authors were active in setting up and delivering the outreach service.

\section{Authors' affiliations}

D A Lewis, National Institute of Communicable Diseases, South Africa A McDonald, G Thompson, J S Bingham, Department of Genitourinary Medicine, Lydia Clinic, 1st Floor Lambeth Wing, Guy's and St Thomas's Hospital NHS Trust, Lambeth Palace Road, London SE1 7EH, UK

\section{REFERENCES}

1 Nicoll A, Catchpole M, Cliffe S, et al. Sexual health of teenagers in England and Wales: analysis of the national data. BMJ 1999;318:1321-2.

2 Low N, Sterne JAC, Barlow D. Inequalities in rates of gonorrhoea and chlamydia between black ethnic groups in south east London: cross sectional study. Sex Transm Infect 2001;77:15-20.

3 Department of Health. National strategy for sexual health and HIV. London: Department of Health, July 2000.

4 Vanhegan G, Wedgwood A. Young people's understanding of safer sex and their attitude to referral for STI screening - two audits from London Brook Advisory Centres. Br J Fam Plann 1999:25:22-4.

5 Beddard D, Chandiok S, James P, et al. A 6-month pilot of a collaborative clinic between genitourinary medicine services and a young person's sexual health clinic. J Fam Plann Repro Health Care 2003;29:40-2.

6 Low N, Daker-White G, Barlow D, et al. Gonorrhoea in inner London: results of a cross-sectional study. BMJ 1997;314:1719-23.

7 Pearson S. Promoting sexual health services to young men: findings from focus group discussions. J Fam Planning Repro Health 2003;29:194-8.

8 Hancock J. Overcoming barriers in boys' and young men's sexual health work. Working with young men 2002;2:28-31.

9 Creighton S, Edwards S, Welch J, et al. News from the frontline: sexually transmitted infections in teenagers attending a genitourinary clinic in south east London. Sex Transm Infect 2002;78:349-51.

10 Wright S, Tobin R, Kell P, et al. A novel condom policy for young attenders at a sexual health clinic. Sex Transm Infect 2001;77:287-8.

11 Department of Health. A pilot study of opportunistic screening for genital Chlamydia trachomatis infection in England (1999-2000): summary report. www.doh.gov.uk.

12 Low N, Connell P, McKevitt C, et al. 'You can't tell by looking': pilot study of a community-based intervention to detect asymptomatic sexually transmitted infections. Int J STD AIDS 2003;14:830-4.

13 Nwokolo N, McOwan A, Hennebry G, et al. Young people's views on provision of sexual health services. Sex Transm Infect 2002;78:342-5. 